\title{
Brain-Derived Neurotrophic Factor Plays a Critical Role in Contextual Fear Conditioning
}

\author{
Ingrid Y.C. Liu, ${ }^{1}$ W. Ernest Lyons, ${ }^{2}$ Laura A. Mamounas, ${ }^{2}$ and Richard F. Thompson ${ }^{1}$ \\ ${ }^{1}$ Neuroscience Program, University of Southern California, Los Angeles, California 90089-2520, and ${ }^{2}$ Department of Pathology, Division of Neuropathology, \\ Johns Hopkins University School of Medicine, Baltimore, Maryland 21205
}

In this study, brain-derived neurotrophic factor (BDNF) heterozygous knock-outs were tested on fear conditioning, and their wild-type littermates were used as controls. Results showed that $\mathrm{BDNF}^{+-}$mice are impaired in contextual learning, whereas tone learning remains intact. Because BDNF is involved in synaptic transmission and contextual learning is hippocampal dependent, we hypothesized that this deficit is attributable to abnormal BDNF-modulated synaptic plasticity in the hippocampus. A "gain-of-function" experiment was performed next by infusing recombinant BDNF protein into the hippocampal formation to investigate whether this deficit can be rescued. Infusion of BDNF protein into the hippocampus appeared to partially restore contextual fear learning of BDNF ${ }^{+/-}$mice. In conclusion, the present study suggests that BDNF plays a critical role in fear conditioning. Loss of one copy of the BDNF gene leads to impairment of contextual fear learning in $\mathrm{BDNF}^{+/-}$. This deficit can be partially rescued by infusing BDNF protein into the hippocampus. Other brain regions interacting with the hippocampus in the context conditioned stimulus pathway, for example, the amygdala, may also require normal BDNF expression levels to fully rescue this impairment.

Key words: BDNF; knock-out; heterozygous; fear conditioning; context; tone

\section{Introduction}

Brain-derived neurotrophic factor (BDNF) is well known for its trophic functions and more recently has been implicated in synaptic modulation, induction of long-term potentiation (LTP), and certain forms of learning and memory (Croll et al., 1998; Mu et al., 1999; Tokuyama et al., 2000; Poo, 2001; Tyler et al., 2002; Yamada et al., 2002). Recent evidence suggests that BDNF signaling may be in a key position to influence the induction of LTP as well as to contribute to neuronal plasticity underlying learning and memory. Notably, BDNF gene expression is regulated by neuronal activity; BDNF activates both presynaptic and postsynaptic tyrosine kinase receptor B (TrkB) receptors; and the presynaptic actions of BDNF include facilitation of neurotransmitter release via synapsin phosphorylation, whereas postsynaptic BDNF-TrkB signaling facilitates activation of both NMDA and non-NMDA receptors (Yamada et al., 2002). Several studies have shown that BDNF has a role in various learning and memory paradigms including hippocampal-dependent tasks such as the water maze (Linnarsson et al., 1997), the radial arm maze (Mizuno et al., 2000), and cerebellum-dependent eyeblink condi-

Received May 19, 2004; revised July 21, 2004; accepted July 21, 2004.

This work was supported by the National Science Foundation Grant IBN-9215069, National Institute of Mental Health Grant 5P01-MH52194, and National Institute on Aging Grant AG14751.

Correspondence should be addressed to Dr. Richard F. Thompson, Neuroscience Program, University of Southern California, Hedco Neuroscience Building 522, 3641 Watt Way, Los Angeles, CA 90089-2520. E-mail: thompson@usc.edu.

W. E. Lyons' and L. A. Mamounas' present address: National Institute of Neurological Disorders and StrokeNational Institutes of Health, Bethesda, MD 20892.

I. Y. C. Liu's present address: Department of Human Genetics, Tzu Chi University, Hualien, 970 Taiwan. DOI:10.1523/JNEUROSCI.1948-04.2004

Copyright $\odot 2004$ Society for Neuroscience $\quad$ 0270-6474/04/247958-06\$15.00/0 tioning (Bao et al., 1998, 1999; Qiao et al. 1998). On the other hand, conditional TrkB null mice exhibit normal learning in simple passive avoidance tasks (Minichiello et al., 1999). Currently, it is not known whether BDNF signaling is involved in emotional learning paradigms such as fear conditioning.

Recently, Hall et al. (2000) reported that BDNF mRNA expression is upregulated in the hippocampal CA1 region $24 \mathrm{hr}$ after contextual fear conditioning, suggesting that BDNF signaling may contribute to synaptic plasticity in this form of learning. Here, we used BDNF heterozygous null $\left(\mathrm{BDNF}^{+/-}\right)$mice to examine the functional role of BDNF signaling in fear conditioning. Unlike BDNF homozygous null mice, these animals have a normal life span, allowing behavioral studies in adult animals. BDNF mRNA and protein levels in the forebrain of this heterozygous line are $\sim 50-70 \%$ of normal (Kolbeck et al., 1999; Lyons et al., 1999), and even partial reductions of BDNF levels can lead to significant behavioral abnormalities (Lyons et al., 1999). Our results indicate that $\mathrm{BDNF}^{+/-}$mice are severely impaired in contextual fear learning, whereas tone learning remains intact. Moreover, these learning deficits could be partially reversed by chronic intraparenchymal administration of recombinant BDNF protein into the hippocampus. Preliminary abstracts of these results were published previously (Liu et al., 2001, 2003). These findings suggest a critical role for the BDNF gene and its protein in contextual fear conditioning, a learning paradigm shown to be dependent on intact hippocampal functioning.

\section{Materials and Methods}

Animals. Fear conditioning was assessed in experimentally naive male $\mathrm{BDNF}^{+1-}$ mice $(n=8)$ and wild-type (WT) littermates $(n=8)$ at 8 weeks of age. Mice were individually housed in plastic and metal cages 


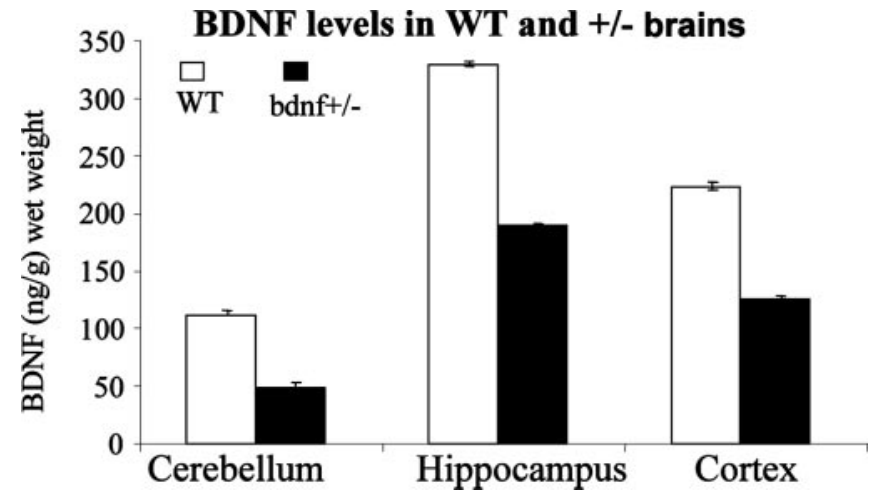

Figure 1. ELISA analysis for mean \pm SEM BDNF protein levels from different brain regions of $\mathrm{WT}_{\text {and }} \mathrm{BDNF}^{+/-}$.

with ad libitum access to food and water and maintained in a climatecontrolled vivarium on a $12 \mathrm{hr}$ light/dark cycle. All test procedures were conducted during the light phase of the cycle. The line of $\mathrm{BDNF}^{+/-}$mice used in these studies was maintained on a C57BL/6 genetic background by backcrossing for 15-18 generations, as described previously (Lyons et al., 1999). The C57BL/6 strain, compared with the DBA/2J strain and the $\mathrm{BALB} / \mathrm{c}$ strain, has been shown to express greater freezing responses after contextual fear conditioning and to retain contextual memories longer (Chen et al., 1996; Balogh et al., 2002). Mice were genotyped by PCR analysis of tail DNA to detect the presence of the neomycin insert. BDNF protein levels were measured by ELISA (Kolbeck et al., 1999) in selected brain regions (including hippocampus) of $\mathrm{BDNF}^{+/-}$mice and were found to be $\sim 50 \%$ of WT (Fig. 1), as previously reported (Korte et al., 1995; Kolbeck et al., 1999).

Pain test. To measure nociception, $\mathrm{BDNF}^{+/-}(n=8)$ and WT $(n=8)$ mice were restrained in a plastic cylinder (inner diameter, $4 \mathrm{~cm}$ ). The tail was put on a hot plate $\left(56^{\circ} \mathrm{C}\right)$, and the onset latency of tail flick was recorded three times with $1 \mathrm{~min}$ intervals.

Vision test. The reaction to light of $\mathrm{BDNF}^{+/-}$mice was examined by shining a bright light in the eye to look for the pupillary reflex (Steel and Hardisty, 2000). The pupillary reflex of $\mathrm{BDNF}^{+/-}$mice was not different from the WT response. During this observation, the lens and cornea were also examined, and no obvious defects were detected. To test visual perception, a black wooden bar was inserted quickly into the home cage, and the escape behavior of mice was observed. The escape times of BDNF ${ }^{+/-}$ and WT were similar (data not shown) when the bar was inserted. Both strains tended to stay away from the bar and looked at it when it moved around in the air.

Auditory test. To assess hearing, animals were anesthetized (ketamine and xylazine) and placed in a sound-attenuated chamber on an isothermal pad. Platinum subdermal needles were inserted on the vertex of the skull and ventrolateral to a pinna. Animals were presented with a $2 \mathrm{kHz}$ tone (10 msec duration; $1 \mathrm{msec}$ rise-fall;100 msec between tones), filtered through a Krohn-Hite filter (model 3700; $1.5 \mathrm{kHz}$ low cutoff; 20 $\mathrm{kHz}$ high cutoff; Krohn-Hite, Brockton, MA). Each mouse was tested with 2000 tone-on $(85 \mathrm{~dB})$ trials and followed by 2000 tone-off $(0 \mathrm{~dB})$ control trials.

The auditory brainstem response (ABR) is widely used to test for hearing in rodents (Steel and Hardisty, 2000). The signal was amplified $(10,000$ gain $)$ and filtered $(300 \mathrm{~Hz}$ low cutoff; $5 \mathrm{kHz}$ high cutoff) through a differential AC amplifier (model 1800;A-M Systems, Carlsborg, WA) into the sound card. The sound card averaged the ABR signal recorded from 2000 trials and calculated the average amplitude (peak-to-peak microvolt) of the ABR during the presentation of the tone.

Apparatus. Both the initial training and subsequent contextual testing were conducted in the same conditioning chamber, whereas tone testing occurred in a novel chamber. The conditioning chamber $(27 \times 28 \times 30.5$ $\mathrm{cm}$ ) was equipped with a speaker and house light modules and was located in a brightly lit room. The front and back of the chamber were constructed of Plexiglas, and the top and sides were constructed of aluminum. The floor of the chamber consisted of 26 stainless steel rods (diameter, $4 \mathrm{~mm}$ ) spaced $10.1 \mathrm{~mm}$ center-to-center that were connected to a shock generator (Precision Controlled Animal Shocker; Coulbourn Instruments, Allentown, PA). The chamber was cleaned with 5\% ammonium hydroxide solution between each subject before conditioning and fear testing.

For tone testing in a novel environment, the new chamber consisted of a wire cage with a plastic bottom $(27 \times 21.5 \times 17 \mathrm{~cm})$, which was located in a dim room. A house light was placed on top of the cage, and a speaker was situated near the left sidewall. A white rear background was placed adjacent to the back of the chamber. The floor consisted of a plastic board covered in bedding material. The chamber was cleaned and scented with $1 \%$ acetic acid between subjects.

Fear conditioning. On day 1 of training, the animals were placed in the conditioning chamber. After a 3 min baseline period, the animals were exposed to 3 tone-footshock pairings (tone, $20 \mathrm{sec}, 85 \mathrm{~dB}, 2 \mathrm{kHz}$; footshock, $1 \mathrm{sec}, 0.3 \mathrm{~mA}$ at the termination of the tone; intertrial interval, 1 $\mathrm{min}$ ). The delivery of the footshock unconditioned stimulus (US) was controlled by software (LabLinc Operant Control Software; Coulbourn Instruments). One minute after the third shock, mice were returned to their home cages. Twenty-four hours later (day 2), fear conditioning to the context of the training chamber was assessed by returning the mice to the conditioning chamber and measuring freezing behavior during an 8 min extinction test. After testing, the animals were returned to their home cages.

Forty-eight hours after training (day 3), mice were tested for auditory fear conditioning in the novel chamber. One minute after being placed in the new chamber, the conditioning tone $(85 \mathrm{~dB} ; 2 \mathrm{kHz})$ was presented continuously for $8 \mathrm{~min}$. Total freezing time was measured as an index of fear memory to tone.

Behavioral data collection. For all procedures, behavior was monitored using a video camera mounted in front of the test chambers. Freezing behavior was defined as the absence of all visible movements of the body and vibrissae aside from movement necessitated by respiration. During 3 min baseline before the first pair of tone and footshock, general activity (i.e., rearing and crossings) was assessed independently every $10 \mathrm{sec}$ by two different observers who were blind to the experimental conditions. Rearing was defined when both front paws are not in contact with the floor, and crossing represents the number of times the mouse crossed the center of the cage. Data from each observer were compared, averaged, and converted to a percentage of total observations [freezing percentage $=($ total freezing time/total testing time $) \times 100 \%]$. All data are expressed as means \pm SEM and analyzed by ANOVA followed by post hoc Tukey tests. During the 3 min baseline measurements, there were no significant differences in the activity levels (crossings and rearings) of $\mathrm{BDNF}^{+/-}$and WT mice (see Fig. 4).

Stereotaxic surgery and BDNF infusion in hippocampus. Animals were deeply anesthetized with ketamine $(80 \mathrm{mg} / \mathrm{kg})$ before surgery. Using a stereotaxic frame, a pair of cannula, each connected to an ALZET 1007D (zcomAlzet, Palo Alto, CA) micro-osmotic pump, was implanted bilaterally in the hippocampus using the following coordinates: anteroposterior, $\pm 1.5 \mathrm{~mm}$; mediolateral, $\pm 1.8 \mathrm{~mm}$ (as measured from bregma); dorsoventral, $1.8 \mathrm{~mm}$ (from flat skull surface). Recombinant human BDNF protein $(30 \mu \mathrm{g} / \mathrm{d}$; Promega, Madison, WI) in artificial CSF (ACSF) or sterile ACSF were continuously infused for 2 weeks (new ALZET 1007D pumps were replaced at the end of the first week) in each hippocampus of $\mathrm{BDNF}^{+/-}$and WT mice. Animals were fear conditioned at the end of infusion.

\section{Results}

\section{Conditioned stimulus and unconditioned stimulus perceptions and locomotor function of $\mathrm{BDNF}^{+/-}$mice} are normal

Because many transgenic mice show developmental deficits that can affect performance in behavioral tasks, we first assessed the mutant $\mathrm{BDNF}^{+/-}$mice for sensory or locomotor impairments that may affect performance in the fear-conditioning paradigm.

Because tone is one of the conditional stimuli in our feartraining paradigm, we first examined $\mathrm{BDNF}^{+/-}$mice with audi- 


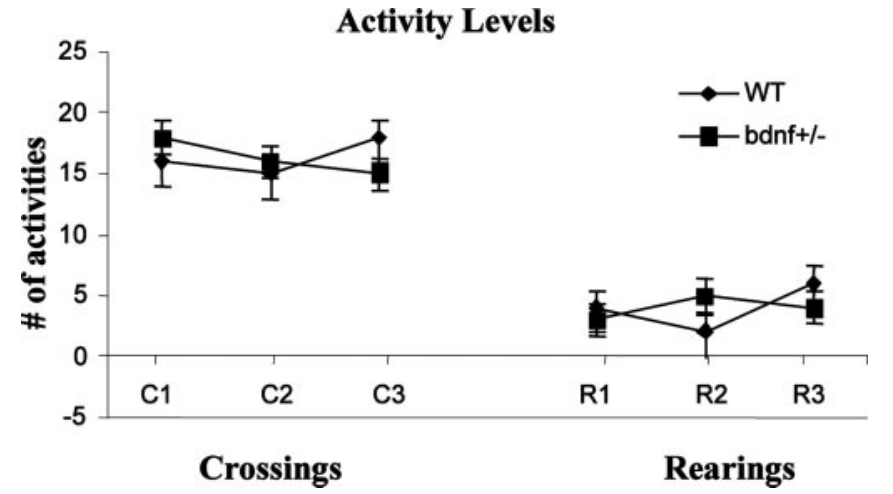

Figure 2. Locomotor activity levels of both $\mathrm{WT}_{\text {and }} \mathrm{BDNF}^{+/-}$groups in the 3 min before receiving the first tone-footshock pairing (mean \pm SEM). Crossing is defined as any time the animal crossed from one side of the testing chamber to the other. Rearing is defined as any time the subject lifted both front paws from the floor of the cage. At baseline, there were no significant differences in activity levels between the two groups.

tory brainstem recordings. Results showed that $\mathrm{BDNF}^{+/-}$mice have comparable hearing to their WT littermates. No significant difference in brainstem auditory responses was observed between $\mathrm{BDNF}^{+/-}$and WT mice (data not shown). Moreover, $\mathrm{BDNF}^{+/-}$ mice demonstrated normal freezing responses to the tone during the tone testing phase of the fear conditioning paradigm (see Fig. 4 ), suggesting that these mutant mice have normal perceptual ability for the tone cue.

During the initial training sessions involving tone-footshock pairings, $\mathrm{BDNF}^{+/-}$mice jumped and vocalized in response to the electric footshock to a similar degree as the WT, suggesting normal pain perception in these mutant mice. To assess nociception in $\mathrm{BDNF}^{+/-}$mice, we measured the heat-induced tail-flick response in these animals. Both $\mathrm{BDNF}^{+/-}$and WT mice exhibited characteristic tail-flick responses in this test, and no significant difference was found in the average latencies to tail flick between the two genotypes, indicating normal pain and heat perception in $\mathrm{BDNF}^{+/-}$mice (data not shown). Visual function appeared normal in the $\mathrm{BDNF}^{+/-}$, as noted in Materials and Methods. During the $3 \mathrm{~min}$ baseline before onset of the first tone-shock pair, crossing and rearing activities of both WT and $\mathrm{BDNF}^{+/-}$were at similar levels (Fig. 2)

\section{$\mathrm{BDNF}^{+/-}$mice exhibit normal tone learning but decreased} contextual learning

During the initial training sessions involving tone-footshock pairing, both $\mathrm{BDNF}^{+/-}$and WT mice exhibited comparable degrees of freezing (data not shown). However, when $\mathrm{BDNF}^{+/-}$ $(n=8)$ and WT $(n=8)$ mice were tested for conditioned fear to context (in the same chamber) $24 \mathrm{hr}$ after fear conditioning, $\mathrm{BDNF}^{+/-}$mice demonstrated substantially less freezing behavior in response to the conditioning chamber $(p<0.05)$ (Fig. 3$)$.

Twenty-four hours after the context testing ( $48 \mathrm{hr}$ after training), the same mice were tested for conditioned fear to tone in a novel chamber. When the tone was presented without the footshock, both $\mathrm{BDNF}^{+/-}$and WT mice exhibited similar freezing responses (Fig. 4). These results indicate that $\mathrm{BDNF}^{+/-}$mice exhibit a selective impairment of contextual fear learning, whereas tone learning remains intact.

\section{Infusion of BDNF protein into the hippocampus partially} restored contextual learning ability of $\mathrm{BDNF}^{+/-}$

Previous studies showed that contextual fear conditioning requires intact hippocampal functioning (Kim and Fanselow, 1992;

\section{Context Test}

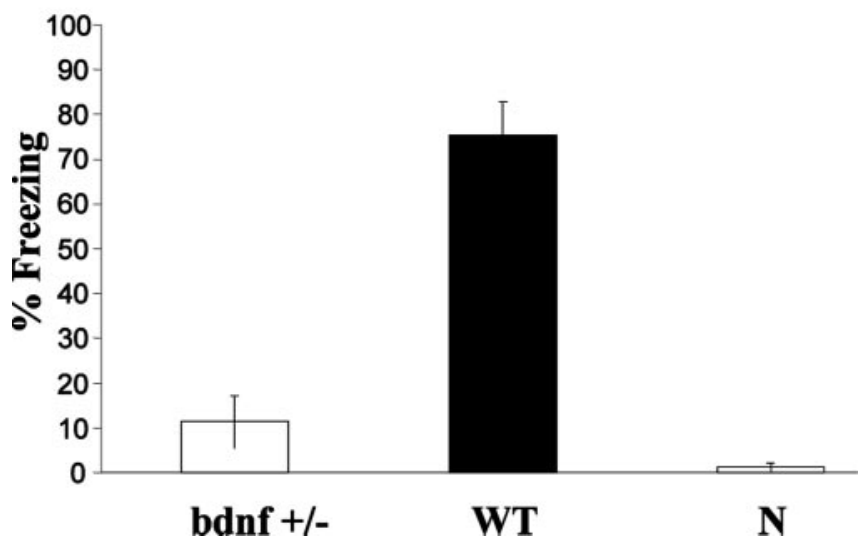

Figure 3. Conditioned freezing to context $24 \mathrm{hr}$ after training. Mean \pm SEM percentage of freezing to context of $\mathrm{BDNF}^{+/-}$was significantly lower than WT $(p<0.05)$. Untrained naive mice (N) showed almost no freezing.

\section{Tone Test}

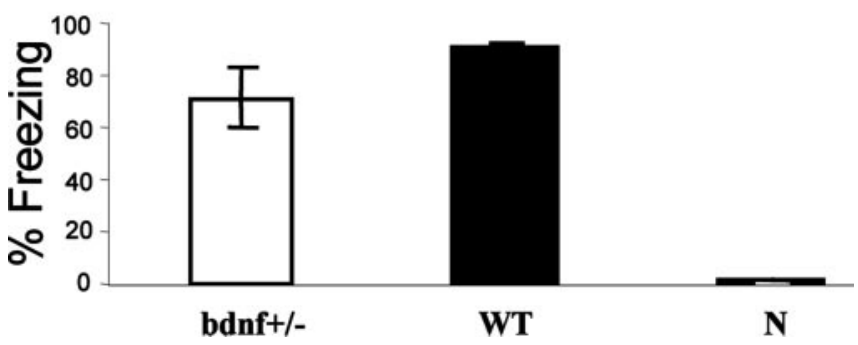

Figure 4. Conditioned freezing to tone $48 \mathrm{hr}$ after training. No significant difference was observed for mean \pm SEM percentage of freezing to tone between BDNF $^{+/-}$and WT. Untrained naive mice $(\mathrm{N})$ showed almost no freezing behavior.

Phillips and LeDoux, 1992), and BDNF expression is upregulated in the CA1 region during contextual fear learning (Hall et al., 2000). Therefore, we hypothesized that the contextual learning impairment in $\mathrm{BDNF}^{+/-}$mice results from the partial loss of BDNF protein in the hippocampus. To test this hypothesis, recombinant human BDNF protein was infused bilaterally at various dosages $(10,20,30,40 \mu \mathrm{g} / \mathrm{d})$ into the hippocampus of $\mathrm{BDNF}^{+/-}$mice for 2 weeks before initiating conditioned fear training. Immunohistochemical localization of the infused BDNF protein revealed a homogeneous distribution within the hippocampus; BDNF immunostaining was observed throughout most of the dorsal hippocampus and parts of the ventral hippocampus (Fig. 5). Cortical areas within $1 \mathrm{~mm}$ surrounding the cannula insertion site were also stained in some animals, but other cortical areas or infrahippocampal structures were not stained. In addition, no gross morphological changes were observed at the light microscope level using Nissl stain (data not shown). All mice appeared well groomed and healthy and exhibited no abnormal behaviors in their home cage.

After training, $\mathrm{BDNF}^{+/-}$mice infused with exogenous BDNF protein (30 $\mu \mathrm{g} / \mathrm{d}$; for 2 weeks in hippocampus) exhibited statistically higher $(p<0.05)$ learned freezing responses in the context test compared with sham control $\mathrm{BDNF}^{+/-}$mice. BDNF infusions in $\mathrm{BDNF}^{+/-}$mice thus partially restored freezing responses to normal levels $(70 \%)$ compared with WT sham controls (infused with ACSF) (Fig. 6, C1-C8). All three groups learned sim- 


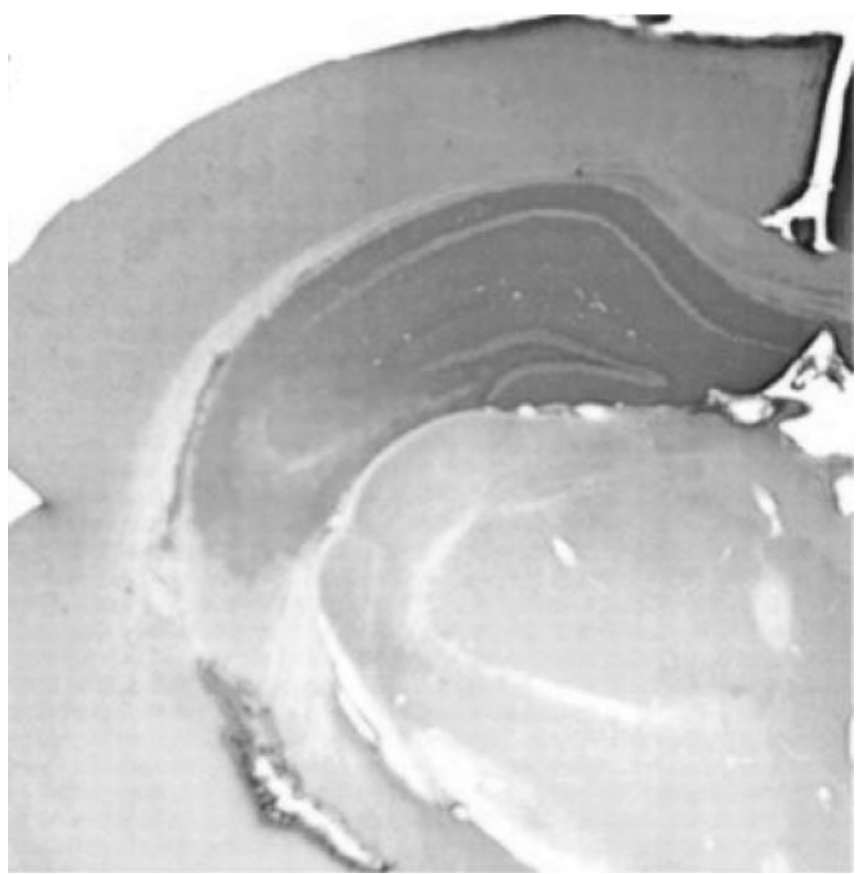

Figure 5. Immunohistochemistry staining with anti-BDNF Ab revealed relatively homogeneous BDNF distribution within the hippocampus.

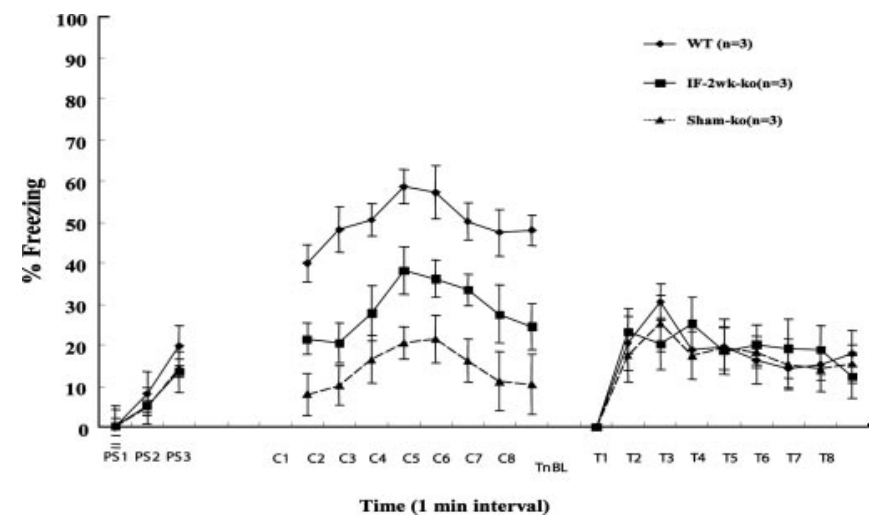

Figure 6. Mean \pm SEM percentage of freezing for BDNF-infused BDNF ${ }^{+/-}$(IF-2wk-ko, infused with BDNF protein at $30 \mu \mathrm{g} / \mathrm{d}$ for 2 weeks), BDNF ${ }^{+/-}$, and WT sham controls during three tone-footshock pairs of fear conditioning training (PS1-PS3), 8 min extinction test in the conditioning context (C1-C8), and 8 min tone test (T1-T8) in a new context. TnBL, No tone baseline; ko, knock-out.

ilarly to tone test (Fig. 6, TnBL-T8). Other dosages (10, 20, 40 $\mu \mathrm{g} / \mathrm{d}$ ) showed no significant effect (Fig. 7). Because the deficit was selective for contextual fear conditioning (whereas conditioning to the tone was normal), it is unlikely attributable to a generalized learning defect or to health-related problems. To ascertain further that changes in the freezing response were not simply caused by altered motor performance (i.e., ability to remain motionless), other behavioral indices including locomotion, grooming, and long-body posture were also measured and no differences were found between the three groups (data not shown).

\section{Discussion}

Our findings indicate that heterozygous $\mathrm{BDNF}^{+/-}$null mice are markedly and selectively impaired in contextual fear conditioning, whereas tone fear conditioning remains intact. These mutant

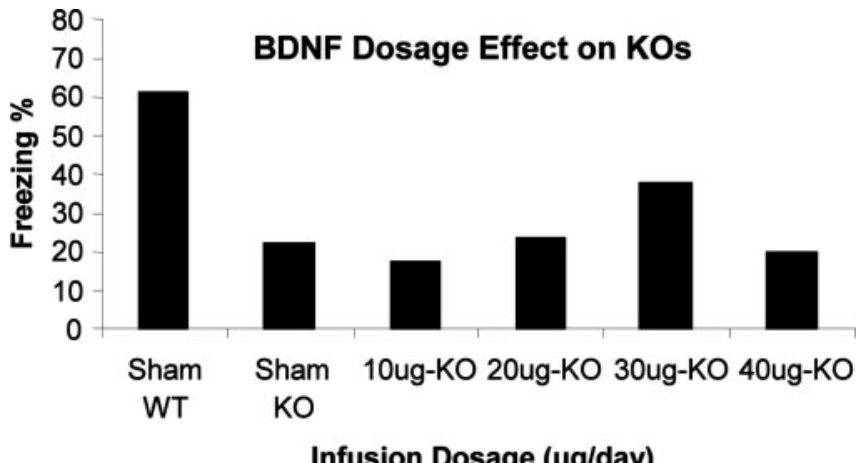

Infusion Dosage (ug/day)

Figure 7. Dosage effect of BDNF infusion on contextual learning deficit of $\mathrm{BDNF}^{+/-}$knockouts (KOs). Only infusion at $30 \mu \mathrm{g} / \mathrm{d}$ can partially restore contextual learning. Other dosages $(10,20,40 \mu \mathrm{g} / \mathrm{d})$ have no significant effect.

mice have about half the normal levels of BDNF protein in forebrain (cortex and hippocampus) and cerebellum. There are no detectable differences in activity levels and in auditory, visual, and somatic sensory-pain responsiveness between the BDNF heterozygotes and wild-type mice. A recent report (Lee et al., 2004), showing that infusion of a BDNF antisense oligodeoxynucleotide in the hippocampus $90 \mathrm{~min}$ before contextual fear conditioning impaired the subsequent expression of conditioned freezing to the context $24 \mathrm{hr}$ later, is in close agreement with our results.

Because context, but not tone fear conditioning, is a hippocampus-dependent learning task (Maren, 2001), our results suggest that the lower levels of BDNF in the hippocampus of $\mathrm{BDNF}^{+1-}$ mice may have contributed to the learning deficit. In support of this view, infusion of exogenous BDNF protein into the dorsal hippocampus of BDNF-deficient mice partially reversed the impairment in context fear conditioning. However, it must be noted that BDNF infusions could have other effects (e.g., increased activity levels in the hippocampus) that are not the same as simply increasing the endogenous levels of the neurotrophin.

Contextual fear learning is dependent on both the hippocampus and the amygdala (Phillips and LeDoux, 1992; Goosens and Maren, 2001). Hippocampal lesions made before training markedly impair the acquisition of conditioned fear to context but impair retention-expression of learned context fear only if made within a month after training (Kim and Fanselow, 1992; Maren and Fanselow, 1997; Anagnostaras et al., 1999). Amygdala lesions, on the other hand, markedly impair both context and tone fear conditioning if made either before or after training (Maren, 2001). Interestingly, classically conditioned context and tone fear are markedly impaired with posttraining amygdala lesions, regardless of time between training and lesion (Maren et al., 1996). However, in inhibitory avoidance training, amygdala lesions are only effective if made soon after training (Parent et al., 1995). These observations raise the possibility that lower BDNF levels in the amygdala may also contribute to the current results (Kim et al., 1993). However, the fact that conditioned fear to tone was at normal levels in both the BDNF heterozygotes and wild-type controls argues against amygdala involvement. Indeed, if the amygdala is involved here, then tone and context fear would have to be very differentially sensitive to BDNF levels in the amygdala. If BDNF levels were reduced substantially below the levels in the heterozygotes, tone fear conditioning may be impaired as well.

Recently, Egan et al. (2003) reported that a single nucleotide 
polymorphism (a val to met substitution) in the prodomain region of the BDNF gene is associated with deficits in hippocampaldependent episodic memory in human subjects. Interestingly, other learning tasks that are less dependent on the hippocampus (e.g., word recall, executive function) are normal in these same subjects. Transfection studies in hippocampal neuronal cultures indicate that the met polymorphism results in impaired intracellular transport and activity-dependent secretion of BDNF. These findings suggest a link between BDNF genotype and hippocampal dysfunction leading to selective memory impairments in humans. In the present study, hippocampal-dependent contextual fear conditioning is likewise selectively vulnerable to the disruption of BDNF signaling in $\mathrm{BDNF}^{+/-}$mice.

BDNF is highly expressed in the hippocampus (Blochl and Thoenen, 1995). Local administration of BDNF enhances field potentials in CA1 when Schaffer collaterals are stimulated (Kang and Schuman, 1995). A consistent finding in the literature is a substantial but not complete impairment in LTP in CA1 of the hippocampus in vitro in both homozygote and heterozygote BDNF knock-out mice (Korte et al., 1995; Patterson et al., 1996). Apparently, long-lasting protein synthesis-dependent LTP is markedly impaired in these mutants (Korte et al., 1998). Furthermore, mice with conditional knock-out of the BDNF TrkB receptor show impaired LTP at CA1 (Minichiello et al., 1999). There is a substantial literature, mostly using mutant and knock-out mice, showing that impairment of LTP in CA1 is associated with impairment in contextual fear conditioning (Chen and Tonegawa, 1997; Silva et al., 1998; Corcoran et al., 2002).

Given the close association between BDNF levels in the hippocampus, amount of LTP in CA1, and degree of context fear conditioning, it would seem likely that other hippocampaldependent memory tasks would also be impaired in BDNF knock-outs. Surprisingly, this is not always the case. Thus, heterozygous BDNF knock-out mice, markedly impaired in LTP in CA1, are not consistently impaired in the Morris water maze (Linnarsson et al., 1997; Montkowski and Holsboer, 1997). Mice with conditional TrkB receptor knock-out show impaired LTP at CA1 synapses and impaired performance in the Morris water maze. However, heterozygous TrkB receptor knock-outs show a partial reduction in CA1 LTP but no impairment in the Morris water maze (Minichiello et al., 1999). These results suggest that the Morris water maze is considerably less sensitive to reductions in BDNF levels in the hippocampus (CA1) than either LTP induction or contextual fear conditioning.

Under some conditions, hippocampal and amygdala systems can interact in the control of spatial memory. Thus, stressactivated glucocorticoid hormones can induce temporary spatial memory retrieval impairments. Infusion of a glucocorticoid receptor agonist in the hippocampus of rat selectively impairs probe-trial retention performance (retrieval) in the Morris water maze. Lesions of the basolateral amygdala a week before training, although not affecting performance in the water maze, per se, blocked the memory retrieval impairment induced by hippocampal infusion of the glucocorticoid receptor agonist (Roozendaal et al., 2003). It is conceivable in the present study that the reduced level of BDNF in the amygdala could somehow interact with the reduced levels in the hippocampus to influence performance in context or tone fear conditioning.

In summary, our results suggest that context, but not tone, fear conditioning is critically dependent on BDNF levels in the hippocampus. Indeed, the fact that infusion of BDNF protein into the hippocampus partially restores context fear learning in the heterozygous knock-outs is strongly supportive. However, more definitive results might be obtained by using conditional, localized knock-out mice. Indeed, such mice have been generated (Morozov et al., 2001). Unfortunately, these mice are reported to freeze all the time and cannot be used for fear conditioning, at least with freezing as the behavioral measure.

\section{References}

Anagnostaras SG, Maren S, Fanselow MS (1999) Temporally graded retrograde amnesia of contextual fear after hippocampal damage in rats: within-subjects examination. J Neurosci 19:1106-1114.

Balogh SA, Radcliffe RA, Logue SF, Wehner JM (2002) Contextual and cued fear conditioning in $\mathrm{C} 57 \mathrm{BL} / 6 \mathrm{~J}$ and DBA/2J mice: context discrimination and the effects of retention interval. Behav Neurosci 116:947-957.

Bao S, Chen L, Qiao X, Knusel B, Thompson RF (1998) Impaired eye-blink conditioning in waggler, a mutant mouse with cerebellar BDNF deficiency. Learn Mem 5:355-364.

Bao S, Chen L, Qiao X, Thompson RF (1999) Transgenic brain-derived neurotrophic factor modulates a developing cerebellar inhibitory synapse. Learn Mem 6:276-283.

Blochl A, Thoenen H (1995) Characterization of nerve growth factor (NGF) release from hippocampal neurons: evidence for a constitutive and an unconventional sodium-dependent regulated pathway. Eur J Neurosci 7:1220-1228.

Chen C, Tonegawa S (1997) Molecular genetic analysis of synaptic plasticity, activity-dependent neural development, learning, and memory in the mammalian brain. Annu Rev Neurosci 20:157-184.

Chen C, Kim JJ, Thompson RF, Tonegawa S (1996) Hippocampal lesions impair contextual fear conditioning in two strains of mice. Behav Neurosci 110:1177-1180.

Corcoran KA, Lu Y, Turner RS, Maren S (2002) Overexpression of hAPPswe impairs rewarded alternation and contextual fear conditioning in a transgenic mouse model of Alzheimer's disease. Learn Mem 9:243-252.

Croll SD, Ip NY, Lindsay RM, Wiegand SJ (1998) Expression of BDNF and trkB as a function of age and cognitive performance. Brain Res 812:200-208.

Egan MF, Kojima M, Callicott JH, Goldberg TE, Kolachana BS, Bertolino A, Zaitsev E, Gold B, Goldman D, Dean M, Lu B, Weinberger DR (2003) The BDNF val66met polymorphism affects activity-dependent secretion of BDNF and human memory and hippocampal function. Cell 112:257-269.

Goosens KA, Maren S (2001) Contextual and auditory fear conditioning are mediated by the lateral, basal, and central amygdaloid nuclei in rats. Learn Mem 8:148-155.

Hall J, Thomas KL, Everitt BJ (2000) Rapid and selective induction of BDNF expression in the hippocampus during contextual learning. Nat Neurosci 3:533-535.

Kang H, Schuman EM (1995) Long-lasting neurotrophin-induced enhancement of synaptic transmission in the adult hippocampus. Science 267:1658-1662.

Kim JJ, Fanselow MS (1992) Modlity-specific retrograde amnesia of fear. Science 256:675-677.

Kim JJ, Rison RA, Fanselow MS (1993) Effects of amygdala, hippocampus, and periaqueductal gray lesions on short- and long-term contextual fear. Behav Neurosci 107:1093-1098.

Kolbeck R, Bartke I, Eberle W, Barde YA (1999) Brain-derived neurotrophic factor levels in the nervous system of wild-type and neurotrophin gene mutant mice. J Neurochem 72:1930-1938.

Korte M, Carroll P, Wolf E, Brem G, Thoenen H, Bonhoeffer T (1995) Hippocampal long-term potentiation is impaired in mice lacking brainderived neurotrophic factor. Proc Natl Acad Sci USA 92:8856-8860.

Korte M, Kang H, Bonhoeffer T, Schuman E (1998) A role for BDNF in the late-phase of hippocampal long-term potentiation. Neuropharmacology 37:553-559.

Lee JL, Everitt BJ, Thomas KL (2004) Independent cellular processes for hippocampal memory consolidation and reconsolidation. Science 304:839-843.

Linnarsson S, Bjorklund A, Ernfors P (1997) Learning deficit in BDNF mutant mice. Eur J Neurosci 9:2581-2587.

Liu YC, Mamounas LA, Thompson RF (2001) Brain-derived neurotrophic factor-deficient mice exhibit decreased contextual learning. Soc Neurosci Abstr 27:955.8.

Liu YC, Mamounas LA, Thompson RF (2003) Infusion of BDNF protein 
into the hippocampus partially restores contextual learning ability of BDNF $^{+/-}$. Soc Neurosci Abstr 29:292.21.

Lyons WE, Mamounas LA, Ricaurte GA, Coppola V, Reid SW, Bora SH, Wihler C, Koliatsos VE, Tessarollo L (1999) Brain-derived neurotrophic factor-deficient mice develop aggressiveness and hyperphagia in conjunction with brain serotonergic abnormalities. Proc Natl Acad Sci USA 96:15239-15244.

Maren S (2001) Neurobiology of Pavlovian fear conditioning. Annu Rev Neurosci 24:897-931.

Maren S, Fanselow MS (1997) Electrolytic lesions of the fimbria/fornix, dorsal hippocampus, or entorhinal cortex produce anterograde deficits in contextual fear conditioning in rats. Neurobiol Learn Mem 67:142-149.

Maren S, Aharonov G, Stote DL, Fanselow MS (1996) N-methyl-Daspartate receptors in the basolateral amygdala are required for both acquisition and expression of conditional fear in rats. Behav Neurosci 110:1365-1374.

Minichiello L, Korte M, Wolfer D, Kuhn R, Unsicker K, Cestari V, RossiArnaud C, Lipp HP, Bonhoeffer T, Klein R (1999) Essential role for TrkB receptors in hippocampus-mediated learning. Neuron 24:401-414.

Mizuno M, Yamada K, Olariu A, Nawa H, Nabeshima T (2000) Involvement of brain-derived neurotrophic factor in spatial memory formation and maintenance in a radial arm maze test in rats. J Neurosci 20:7116-7121.

Montkowski A, Holsboer F (1997) Intact spatial learning and memory in transgenic mice with reduced BDNF. NeuroReport 8:779-782.

Morozov A, Yin D, Malleret G, Santorelli L, Hen R, LeSauter J, Silver R, Dragatsis I, Kandel E (2001) Generation and characterization of mice with the conditional knockout of BDNF. Soc Neurosci Abstr 27:686.8.

Mu JS, Li WP, Yao ZB, Zhou XF (1999) Deprivation of endogenous brainderived neurotrophic factor results in impairment of spatial learning and memory in adult rats. Brain Res 835:259-265.

Parent MB, Quirarte GL, Cahill L, McGaugh JL (1995) Spared retention of inhibitory avoidance learning after posttraining amygdala lesions. Behav Neurosci 109:803-807.

Patterson SL, Abel T, Deuel TA, Martin KC, Rose JC, Kandel ER (1996) Recombinant BDNF rescues deficits in basal synaptic transmission and hippocampal LTP in BDNF knockout mice. Neuron 16:1137-1145.

Phillips RG, LeDoux JE (1992) Differential contribution of amygdala and hippocampus to cued and contextual fear conditioning. Behav Neurosci 106:274-285.

Poo MM (2001) Neurotrophins as synaptic modulators. Nat Rev Neurosci 2:24-32.

Qiao X, Chen L, Gao H, Bao S, Hefti F, Thompson RF, Knusel B (1998) Cerebellar brain-derived neurotrophic factor-TrkB defect associated with impairment of eyeblink conditioning in stargazer mutant mice. J Neurosci 18:6990-6999.

Roozendaal B, Griffith QK, Buranday J, De Quervain DJ, McGaugh JL (2003) The hippocampus mediates glucocorticoid-induced impairment of spatial memory retrieval: dependence on the basolateral amygdala. Proc Natl Acad Sci USA 100:1328-1333.

Silva AJ, Kogan JH, Frankland PW, Kida S (1998) CREB and memory. Annu Rev Neurosci 21:127-148.

Steel KP, Hardisty R (2000) Assessing hearing, vision and balance in mice, p 35. University Park, Nottingham, UK: MRC Institute of Hearing Research.

Tokuyama W, Okuno H, Hashimoto T, Xin LY, Miyashita Y (2000) BDNF upregulation during declarative memory formation in monkey inferior temporal cortex. Nat Neurosci 3:1134-1142.

Tyler WJ, Alonso M, Bramham CR, Pozzo-Miller LD (2002) From acquisition to consolidation: on the role of brain-derived neurotrophic factor signaling in hippocampal-dependent learning. Learn Mem 9:224-237.

Yamada K, Mizuno M, Nabeshima T (2002) Role for brain-derived neurotrophic factor in learning and memory. Life Sci 70:735-744. 